\title{
Directions of modernization of systems for ensuring the quality of construction of nuclear power facilities
}

\author{
Pavel Zhuravlev, Evgeniy Bachus and Irina Markova* \\ Moscow State University of Civil Engineering, Yaroslavskoe shosse, 26, Moscow, 129337, Russia
}

\begin{abstract}
Solving the problems of quality assurance is an integral element of the development strategy of any industry, including the investment and construction sector. Ensuring product quality is not only a competitive advantage, but also helps to reduce unforeseen resources and time costs from the occurrence of nonconformities, which has a positive effect on the economic condition of the manufacturer. The article discusses areas of modernization of quality assurance systems for the construction of nuclear power facilities.
\end{abstract}

\section{Introduction}

Quality assurance issues become extremely important in the implementation of investment and construction activities in the field of nuclear energy use, since inconsistencies that may arise as a result of poor quality assurance of construction products in the construction of nuclear power facilities of the most representative nuclear power facilities (NPF) in terms of potential hazard are not only an extremely undesirable event, but can also lead to significant environmental, and political consequences. Solving the problems of quality assurance is an integral element of the development strategy of any industry, including the investment and construction sector. The implementation of such activities at nuclear power facilities is currently a priority, taking into account the growing interest of foreign countries not only in nuclear power facilities of Russian design, but also in other nuclear facilities of the nuclear cluster. Quality assurance in the implementation of investment and construction activities in the use of nuclear energy, the priority area of activity of not only construction organizations, but also other participants in the investment process, requires the formation and implementation of new organizational forms and schemes for the implementation of such activities.

\section{Methods}

Quality control as one of the main elements of the general system of construction organization requires modernization in order to ensure the solution of the tasks of the construction of nuclear facilities: reducing the cost and construction time. In the course of

\footnotetext{
* Corresponding author: markova@mgsu.ru
} 
the scientific research conducted by specialists of the corporate department of the construction of nuclear facilities of NRU MGSU, it was found that the development of quality assurance systems for the construction of nuclear power facilities (NPF) can take place in the following areas:

1. Quality engineering.

2. Rationing of labour and resource costs in the composition of works to ensure the quality of construction, including nuclear facility (NPF).

3. Planning and regulation of quality assurance measures at the stages of the life cycle of a nuclear power $f$ facility (NPF), including using BIM-technologies.

4. Evaluation of the effectiveness of the corporate quality assurance system for the construction of nuclear power facility (NPF).

5. Automated quality assurance systems for construction of technically complex and unique objects. Application of cyber-physical systems in construction.

\section{Results}

Let us consider in more detail the direction of development of quality assurance systems for construction of nuclear power facilities.

\subsection{Quality engineering}

National Standard of the Russian Federation GOST R 57306-2016 "Engineering. Terminology and basic concepts in the field of engineering" defines, as a subject of engineering, intellectual activity in the creation of an object, the organization of interaction between the parties involved in its creation. In this case, it is indicated that the center of gravity of engineering activity is in the sphere of organizing the design, construction, construction, and programming.

On this basis, engineering is terminologically identified as engineering and consulting activity, the essence of which is the solution of engineering problems related to the creation or improvement of products, systems or processes.

Thus, engineering is a special combination of certain types of activities that contribute to obtaining a new, in some cases synergistic, result, an unattainable simple sequence of individual private research processes (research), designing, organizing, creating, operating and using the object itself.

In this regard, the work initiated by the State Atomic Energy Corporation ROSATOM to create a similar document for the investment and construction sector and ongoing public discussion as a draft GOST "Engineering in construction. The terms and definitions" states that engineering in construction:

- is an independent professional activity, implemented by engineering companies and consulting engineers;

- carried out on a reimbursable contractual basis, that is, it has a commercial character;

- contains a set of engineering, intellectual and consulting services, the ultimate goal of which is to achieve the best results of implementing investment and construction projects throughout their life cycle;

- is based on intellectual development, control and implementation of technical, technological, organizational, managerial, financial and economic and other impacts on the implementation of investment and construction projects in accordance with their objectives; 
- embodied in the useful effect which may have a tangible expression (design, engineering and other documentation) or it may not have (management, training, etc.).

Therefore, investment projects and their implementation processes, which provide for new construction, reconstruction, technical re-equipment of objects of any purpose on the basis of modern scientific approaches, serve as the subject area of engineering in construction. This fact indicates the validity of the inclusion in this developed standard of key terms in the sphere of investment and construction projects management.

By examining and analysing the types of engineering in construction, it is possible to identify quality engineering as the formation and organization of a set of interrelated activities aimed at creating and developing corporate quality assurance systems based on modern scientific achievements, international standards and domestic regulatory documents.

\subsection{Normalization of labour and resource costs in the work of ensuring the quality of construction, including nuclear power facilities}

The problem of ensuring the quality of construction products requires a focus on the costs of investment and construction activities and their impact on corporate performance, identifying those groups of costs to ensure the quality of construction products, which can be provided in advance.

Close attention to the indicator of costs for quality assurance of construction products is due in large part to the fact that the share of such costs in construction costs is constantly growing. For example, studies have shown that the maximum amount of costs for quality assurance can be $15-20 \%$ of the cost of construction, and their minimum level is $2.5 \%$.

On the basis of the conducted research it can be asserted that the standardization of the costs of product quality assurance is the basis for the formation of a set of measures aimed at:

- planning activities, one way or another related to the quality of construction products, in order to achieve the best technical and economic indicators;

- establishing the amount of financial resources necessary to carry out works to improve the quality of construction products;

- forecasting the costs necessary to manage the activities of the entire construction organization.

Below is an approximate nomenclature of elements for the supply of quality construction products (Table 1).

Table 1. Approximate nomenclature of elements for the supply of quality construction products

\begin{tabular}{|c|c|c|}
\hline No. & $\begin{array}{l}\text { The name of the } \\
\text { integrated group of } \\
\text { costs / types of work }\end{array}$ & Name of types of work / elemental costs \\
\hline 1 & \multirow{6}{*}{$\begin{array}{c}\text { Costs (work) on marriage } \\
\text { prevention }\end{array}$} & \\
\hline 1.1 & & Planning quality of building products and process control \\
\hline 1.1.a & & $\begin{array}{l}\text { Quality planning in the division (service) technical quality control of } \\
\text { construction products }\end{array}$ \\
\hline 1.1.b & & $\begin{array}{l}\text { Remuneration and costs associated with the implementation and } \\
\text { expansion of work on the prevention of marriage }\end{array}$ \\
\hline 1.2 & & $\begin{array}{l}\text { Design and improvement of methods of establishing quality and } \\
\text { development management quality assurance of construction } \\
\text { products }\end{array}$ \\
\hline 1.3 & & $\begin{array}{l}\text { Quality planning of a separate function outside the quality assu } \\
\text { management loop }\end{array}$ \\
\hline
\end{tabular}




\begin{tabular}{|c|c|c|}
\hline 1.4 & & Training in quality assurance of construction products \\
\hline 1.5 & & $\begin{array}{l}\text { Other additional work and associated costs for the prevention of } \\
\text { rejects }\end{array}$ \\
\hline 2 & \multirow{11}{*}{$\begin{array}{l}\text { Costs (work) to assess } \\
\text { product quality }\end{array}$} & \\
\hline 2.1 & & \begin{tabular}{|l|} 
Verification of materials entering the organization \\
\end{tabular} \\
\hline 2.2 & & Laboratory verification of incoming materials \\
\hline 2.3 & & Material verification during construction \\
\hline 2.4 & & $\begin{array}{l}\text { Establishing a set of quality control measures for construction } \\
\text { products }\end{array}$ \\
\hline 2.5 & & Quality control of construction products \\
\hline 2.6 & & $\begin{array}{l}\text { Approval of quality parameters by the customer and the operating } \\
\text { organization }\end{array}$ \\
\hline 2.7 & & \begin{tabular}{|l|} 
Caring for the equipment, its regulation, inspection and control \\
\end{tabular} \\
\hline 2.8 & & Relearn the control and inspection of construction products \\
\hline 2.9 & & $\begin{array}{l}\text { Practical approbation in the framework of commissioning and pilot } \\
\text { production }\end{array}$ \\
\hline 2.10 & & Evaluation of conformity of stocks material and technical resources \\
\hline 3 & \multirow{6}{*}{$\begin{array}{l}\text { Costs (work) due to the } \\
\text { presence of internal } \\
\text { defective products }\end{array}$} & \\
\hline 3.1 & & Defective construction products \\
\hline 3.2 & & Correction of defective construction products \\
\hline 3.3 & & Determination of causes of the rejects of construction products \\
\hline 3.4 & & Re-control and checking \\
\hline 3.5 & & $\begin{array}{l}\text { Quality control materials and raw materials, the establishment of the } \\
\text { causes of low quality of products }\end{array}$ \\
\hline 4 & \multirow{7}{*}{$\begin{array}{l}\text { Costs (work) due to the } \\
\text { presence of external } \\
\text { defective products }\end{array}$} & \\
\hline 4.1 & & Payment of compensation to the operating organization \\
\hline 4.2 & & Warranty service for construction products \\
\hline 4.3 & & Disposal (dismantling, demolition) or repair of structural elements \\
\hline 4.4 & & Constructions insurance \\
\hline 4.5 & & Engineering error correction costs \\
\hline 4.6 & & $\begin{array}{l}\text { The cost of the correction of errors identified during the construction } \\
\text { process }\end{array}$ \\
\hline
\end{tabular}

Identification of costs for quality assurance of construction, including NPF, by means of their rationing allows the construction organization to continue the strategic line in its sustainable and progressive development and make the most rational use of the limited resources available to it.

In the framework of modern economic concepts, it is very difficult to verify the concept of costs for quality assurance of products (including construction products) due to the fact that in one way or another all activities related to the production of products are related to its quality. This fact makes it difficult to determine the precise definition of the cost of quality assurance, since there is no difference between the costs of quality assurance and the costs of other activities.

To date, two methodological approaches to this problem are singled out from the whole spectrum. According to the first approach, the cost of quality assurance is a combination of the costs of quality control, as well as the identification of internal and external defective products. In the second approach, the costs of product quality assurance are a tool for determining the resources in value terms spent in the wrong direction.

\subsection{Planning and regulation of quality assurance activities at the life-cycle stages of the nuclear power facility, including using BIM-technologies}

During the design, production and operation of nuclear facilities, one of the main tasks is to ensure the quality of technological processes and construction products under various 
operating conditions. As scientific research and practical experience show to save limited resources and time, life cycle management uses software complexes based on identifying the features of production and operation of a separate component, a node, the ability to automate engineering tasks and support decision-making in production and operation.

Currently, due to the growing complexity of managing the life cycle of NPF and increasing international competition, as well as the high level of requirements for users of nuclear power facilities, it is necessary to apply end-to-end and integrated adaptive management at life-cycle stages using BIM technologies and the use of cyber-physical systems.

Planning and regulation of quality assurance measures at the stages of the life cycle involves the creation of complex anthropotechnical systems that provide management of all processes, their complexes, stages and covering pre-project studies, design, production, operation, decommissioning of NPF.

The key problems can be the fact that in practice software is used that is limited to the design and sometimes construction stages, while there are no unified requirements for the creation and operation of such systems, which makes the information unstructured and its transfer across the life cycle stages is difficult.

Information about the quality and requirements for it may change over time, so the programs, plans and regulations are also transformed. As a result, quality assurance systems must respond timely manner to changes occurring during its life cycle, and BIM systems should provide for the possibility of upgrading and updating during their operation.

Planning and regulation of quality assurance activities at NPF is a complex task due to the large number of construction participants, the high level of uncertainty due to the significant range and intensity of the external and internal environments, and the need for timely preventive maintenance of structural elements of buildings and structures, as well as process equipment.

Data on the current state of NPF quality in a BIM-system should be based on the actual information model developing together with the object, integrating the regulatory, operational and user requirements for it, information on the principles and parameters of operation, operation features, current status, etc. At the same time, a methodological approach is needed that will allow using multi-criteria real-time optimization to return current plans violated by unforeseen events to specified parameters, primarily in those works and events where the deviation is maximal or which lie on the critical path.

\subsection{Evaluation of the effectiveness of the corporate quality assurance system for the construction of nuclear power facilities}

In order to objectively assess the effectiveness of the corporate quality assurance system for the construction of NPF, it is necessary to identify a nomenclature of indicators that determine the quality of construction products and ensure the adequacy and accuracy of its assessment, i.e., a set of interrelated planning, design, functional and other characteristics that make it possible to cover regulatory, operational and consumer requirements for quality of nuclear power facilities.

Forming such a system of performance indicators, you should pay attention to ensure that they meet the following requirements:

- had high content, adequacy and reliability;

- yielded to formalization, had the simplicity of calculation and actualization;

- expected modernization of the quality assurance system;

- integrated quantitative and qualitative characteristics;

- assuming the targeting of the effectiveness evaluation (for example: for construction participants), ensure comparability of the results of such analysis; 
- was interconnected with the technological and operational and production indicators of the NPF.

The key imperatives of the process of evaluating the effectiveness of quality assurance systems for nuclear facilities, first and foremost, should include the requirements of reliability, adequacy and meaningfulness of the parameters. Developing the procedural and substantive parts of the assessment, it is necessary to take into account that each indicator should, without repeating the others, characterize a certain property of construction products and be associated with operational and production indicators. In this regard, the quality indicators that characterize individual properties may have a physical or value dimension or be relative (in points, fractions of a unit).

The generalized indicator, depending on the purpose of the evaluation, is determined by the appropriate method, for example: as an integral or average weighted index.

\subsection{Automated systems ensure the quality of construction of technically complex and unique objects. Use in the construction of cyber-physical systems.}

The modern feature of the development of technical and economic systems, including in the investment and construction sector, is the integration of the latest technical, technological, telecommunication means, software systems into a single cyber-physical system, which allows you to create a unified automated corporate information environment that makes it possible in automatic mode receiving information about objects, processing it on the basis of economic-mathematical methods, models and high-performance computers programs and the transfer by means of telecommunication means to specialists for making timely and adequate management decisions at the stages of the life cycle of nuclear facilities.

The creation and operation of quality assurance systems for construction of technically complex and unique objects are closely related to the development of information technologies that transform as they move to the upper levels of the corporate hierarchy into information and analytical systems that are not limited to collecting and processing existing data, but implying the satisfaction of specific users in information based on the use of special, in some cases, unique methods and means of its generation, which compensation of incomplete information, the formation of information data, processing, accumulation and presentation in a convenient form, the identification of the current state and trends in the development of objects.

The functioning of automated quality assurance systems for the construction of technically complex and unique objects is associated with the establishment of the order of formation of information arrays necessary for operational and production activities, filling the missing data with special methods, organization of sufficient, reliable information flows. Considering this issue already in the context of quality engineering, the formation and functioning of information and analytical systems can be represented in two planes:

- designing a rational structure and composition of the information system;

- efficient management of information flows.

\section{Discussions}

Based on the obtained results of the conducted research, the following conclusions can be drawn:

1. The quality management of the project includes the processes and actions of the organization, which are determined by the policy in the field of quality assurance, as well as the purpose of the project and the areas of responsibility of its participants so that the 
building products meet the established requirements and needs of the facility user.

2. Classification of resource supply of product quality makes it possible to compare the costs of preventing rejects, the costs of assessing product quality as inputs to the quality management system, with costs due to the presence of internal and external defective products, and exit from this system, as well as being the basis for normalizing these labour costs and resources.

3. The BIM-system should support the work of the information model on the basis of semantic and neural networks, which is necessary for the formation of knowledge bases, as well as for the variability in the adoption of managerial decisions. This approach provides the competitive advantages of the BIM-system, as a result of the improvement of the quality of construction of the NPF and the effectiveness of solutions for managing their life cycle, the ability to connect to a common system of new facilities, high efficiency, reliability, as well as reducing the costs of its use and maintenance, the risks of its operation.

4. The need to identify the effectiveness of the corporate system to ensure the quality of construction of nuclear power facilities can arise in the process of solving various industrial tasks, for example, when:

- use in the production of new materials, technologies. Engineering solutions or liquidation (decommissioning) of facilities;

- certification and certification;

- analysis of changes in the quality of construction;

- assessment of the complementarity of corporate technical regulations and standards;

- estimated rationing and pricing;

- solving other problems.

5. Information-analytical system of ensuring the quality of nuclear facilities is an integrated system of design and management of information on the quality of all construction and operating of nuclear power facilities on the stages of their life cycle. As a result the set of knowledges of data domain structured for formalization of the decisionmaking process that determine the content of the information systems and technology, are the genesis of cyber-physical systems. Use in turn of such systems in the investment and construction sector point to the need for integrated thinking, involving decisions based on a wider range of indicators, principles of comprehensiveness, complexity and imperatives of the sustainable development concept.

\section{References}

1. S.B. Sborshikov, Plekhanov Russian Academy of Economics 305 (2012)

2. P.A. Zhuravlev, Bulletin of the Belgorod STU 198 (2017)

3. P.A. Zhuravlev, Bulletin of the Irkutsk STU 104 (2015)

4. E.E. Ermolaev, Bulletin of State University of Management 3 (2013)

5. A.A. Aleksanin, Bulletin of MGSU 164 (2009)

6. Y.V. Zharov, Journal of Industrial and Civil Engineering 69 (2013)

7. N.M. Shoumeiko, Bulletin of Civil Engineers 53 (2015)

8. E.E.Bachus, N.V.Lazareva, Bulletin of the Belgorod STU 186 (2017)

9. N.V. Lazareva, E.E.Bachus, Scien.-Th. Journ. of the Belgorod STU 220 (2017)

10. P.A. Zhuravlev, E.E.Bachus Bulletin of Civil Engineers 76 (2018)

11. E.E. Bachus, Scientific Review, 20 (2016)

12. A.V. Lyapin, B.Y. Lyapin., Scientific Review, 251 (2016) 
13. N.V.Lazareva, Newspaper IGSU 178 (2015)

14. T.V. Prokhorova, Natural and technical sciences 6 (2015)

15. S.B. Sborshikov, D. M. Leybman, Scientific Review, 18 (2016)

16. U.N. Domojilov, Bulletin of MGSU 12 (2007) 